\title{
Correspondence
}

\section{Inbalation induction with sevoflurane}

We read with interest the editorial by Goresky and Muir. ${ }^{1}$ Perhaps the time has come to reevaluate reliance on $i v$ induction of anaesthesia for adults and to consider offering inhalational induction. Recently, we offered 100 consecutive patients scheduled for minor gynaecological procedures the choice of an inhalational anaesthetic with sevoflurane or ip induction of anaesthesia using propofol. It was explained that patients who chose the inhalational method would not require an iv cannula until asleep. Inhalational anaesthesia was induced with sevoflurane $8 \%$ and maintained with sevoflurane $1-2 \%$ in oxygen $50 \%$ and nitrous oxide. Exclusion criteria included mask phobia, reflux oesophagitis, cardiac or respiratory disease, obesity and allergy to sevoflurane. When assessed by a blinded observer after surgery, the acceptability rate for inhalational anaesthesia was $86 \%$. Most (93\%) patients found it a pleasant experience and most of these $(87 \%)$ would chose the mask again.

This study highlights the need to reevaluate this means of induction in adult patients. Several studies have shown rapid induction and recovery from anaesthesia with sevoflurane in the paediatric population. ${ }^{2-5}$ Do we not owe it to our patients to at least offer this form of induction to adults without a mask phobia who are undergoing minor procedures?

J. McGinley FFARCSI

L. Briggs FFARCSI

M. Carey MD FFARCSI

Dept. of Anaesthesia,

Coombe Women's Hospital

Dublin 8

Ireland

\section{REFERENCES}

1 Goresky GV, Muir J. Inhalation induction of anaesthesia. Can J Anaesth 1996; 43: 1085-9.

2 Black $A$, Sury MRJ, Hemington L, Howard R, MackersieA, Hatch DJ. A comparison of the induction characteristics of sevoflurane and halothane in children. Anaesthesia 199; 51: 539-42.

3 Lerman J, Davis PJ, Welborn LG, et al. Induction, recovery, and safety characteristics of sevoflurane in children undergoing ambulatory surgery. Anesthesiology 1996; 84: 1332-40.

4 Piat V, Dubois MC, Johanet S, Murat I. Induction and recovery characteristics and haemodynamic responses to sevoflurane and halothane in children. Anesth Analg 1994; 79: 840-4.

5 Sarner JB, Levine M, Davis PJ, LermanJ, Cook DR, Motoyama EK. Clinical characteristics of sevoflurane in children. Anesthesiology 1995; 82: 38-46.

\section{$R E P L Y$}

Observations in adults similar to those documented by Dr. McGinley, Briggs, and Carey have been presented previously. In the Journal, Doi and Kazuyuki reported in $1993^{1}$ that sevoflurane was the least irritant of four inbalational anaesthetic agents when administered to adult male volunteers using tidal breathing of standardized inbaled concentrations.

Thwaites, Edmends and Smith conducted a randomized, double-blind comparisons of $8 \%$ sevoflurane and propofol as induction agents for day-case cystoscopy in 102 patients. They also found in $14 \%$ of their subjects that inhalation induction with sevoflurane was unpleasant and $24 \%$ were unwilling to receive the same induction again.

Others have reported that a vital capacity breath in adults provides a faster induction with fewer excitatory phenomena than does an induction using tidal breathing. In the Journal, Turino and Kimura reported that induction times were faster and induction complications were fewer with single breath sevoflurane than with balothane induction. In a follow-up these investigators demonstrated in adult volunteers that a vital capacity manoeuvre provided faster induction with fewer excitatory phenomena. ${ }^{4}$ Using a vital capacity breath to facilitate inbalation induction BK Pbilip, $J B$ Gross, $M H$ Sloan, and JH Philip demonstrated, at an exhibit at the 1996 ASA meeting that "vital capacity inhalation was a good alternative to iv induction of anaesthesia." Clearly, inhalation induction with sevoflurane in cooperative adults can be even more effective than tidal breathing when an initial vital capacity breath is used.

Gerald V. Goresky MDCM FRCPC

Calgary, Alberta

John G. Muir MB CHB FRCA FRCPC

Halifax, Nova Scotia

\section{REFERENCES}

1 Doi $M, I k e d a K$. Airway irritation produced by volatile anaesthetics during brief inhalation: comparison of halothane, enflurane, isoflurane and sevoflurane. Can J Anaesth 1993; 40: 122-6. 